\title{
México y las instituciones republicanas en el exilio: del apoyo del Cardenismo a la instrumentación política del Partido Revolucionario Institucional, 1939-1977
}

por

\author{
Jorge de Hoyos Puente ${ }^{1}$ \\ Universidad de Cantabria
}

\begin{abstract}
Este artículo realiza una revisión de las circunstancias del apoyo de los sucesivos gobiernos mexicanos hacia la II República en el exilio a lo largo de la dictadura franquista. Esta ayuda supuso uno de los principales balones de oxígeno para la legalidad republicana en el exilio, no exenta, sin embargo, de mitificaciones. Pretendemos abordar algunas de las principales claves para entender esa actitud sostenida en el tiempo por parte de las autoridades mexicanas.
\end{abstract}

Palabras clave: México; Partido Revolucionario Institucional (PRI); España; exilio republicano.

La historia de las relaciones internacionales entre España y México a lo largo del siglo XX está marcada de forma irremediable por el resultado de la Guerra Civil española y su posterior exilio². Si con la proclamación de la II República en España las relaciones diplomáticas con su antigua colonia se

1 Doctor en Historia Contemporánea por la Universidad de Cantabria, es miembro del Grupo de Investigación Historia y Cultura Contemporánea de la Europa del Sur y de América Latina, dirigido por el profesor Manuel Suárez Cortina, director del proyecto «Federalismo, Estado y nación en la Europa del Sur y América Latina en la época liberal, una perpectiva comparada». Ref.: HAR 2012-35245 . En la actualidad es Visiting Scholar en la Universidad de Columbia, gracias al programa Nacional de Movilidad de Recursos Humanos de Investigación en el marco del Plan Nacional de Investigación Científica, Desarrollo e Innovación Tecnológica 2008-2011.

2 Para las relaciones entre España y México véase Sánchez Andrés y Pereira Castañares, 2010. 
normalizaron, el inicio de la Guerra Civil puso de manifiesto el apoyo inequívoco del gobierno mexicano, presidido por el general Lázaro Cárdenas, hacia la democracia española ${ }^{3}$. México desplegó su ayuda durante la contienda civil en diversos frentes, desde el armamentístico hasta el diplomático, pasando por la recepción de intelectuales en la Casa de España y los conocidos como los niños de Morelia. Suficientemente conocidos, gracias a la historiografía de ambos países, son los esfuerzos realizados en ese sentido ${ }^{4}$. Tras la derrota republicana, México abrió sus fronteras a los perdedores de la guerra española, para salvaguarda de sus vidas, en un contexto internacional cada vez más complejo, con la vieja Europa asolada por el totalitarismo nazi-fascista y la inacción de las democracias, desbordadas por los acontecimientos.

México se convirtió entonces en la tabla de salvación para un par de decenas de miles de españoles que comenzaron a adorar al presidente Cárdenas como muestra de gratitud, elevándolo a los altares laicos de los republicanos, convirtiéndolo en uno de los mitos fundacionales del exilio republicano ${ }^{5}$. Desde 1939, México y la España «victoriosa» mantuvieron sus relaciones diplomáticas oficialmente suspendidas, por decisión unilateral de los sucesivos gobiernos mexicanos. El discurso del México oficial sostuvo durante décadas que esa situación era resultado de la tradición política internacional de sus gobiernos y de los compromisos alcanzados con la legalidad republicana, por encima de cualquier otro tipo de intereses. En los últimos años, las historiografías española y mexicana han ido matizando esta imagen idílica con el fin de completar la visión de las relaciones entre estos dos países en los años de la dictadura franquista. Sin buscar refutar la importancia y generosidad acreditada por las autoridades mexicanas, los trabajos de Nuria Tabanera o Rosa Pardo y obras como la coordinada por Clara E. Lida, México y España en el primer franquismo, 1939-1950, han puesto en evidencia la necesidad de contraponer a esa idealización una lectura sosegada de la multitud de evidencias y pruebas que muestran una realidad un tanto diferente ${ }^{6}$.

En las siguientes páginas trataré de realizar un análisis de la evolución de la actitud de los sucesivos gobiernos mexicanos hacia los republicanos españoles, centrándome principalmente en la relación con los gobiernos de la II República en el exilio, atendiendo a la política interna y las estrategias diplo-

3 Tabanera, 1993: 26-35.

4 Para la actividad diplomática véase Guillén, 1976. Serrano Migallón, 1981. Paz Sánchez, 1986. Lida, 1995: 66-72. Ortuño, 2007. Tirado, 2007. Para los niños de Morelia véase Pla, 1985. Payá, 1985. Sánchez Andrés, 2002.

5 Hoyos Puente, 2008.

${ }^{6}$ Para esta cuestión Lida, 2001. Tusell, 1997. Pardo, 1995. 
máticas del país. A lo largo de los casi cuarenta años que duró la dictadura española, México recorrió una profunda transformación que afectó de forma notable a esas relaciones. El proceso de derechización y oligarquización del Partido Revolucionario Institucional (PRI) influyó lógicamente en la disminución del grado de implicación política con respecto a la causa republicana, aplastada por sus divisiones internas y la compleja deriva internacional que dio origen a la Guerra Fría. Trataremos de mostrar algunos ejemplos de la instrumentalización política que las autoridades mexicanas realizaron de la causa republicana en función de sus propios intereses.

De la llegada de los Refugiados a la CREACIÓN DEL PRI.

Con la llegada a México de las grandes expediciones de refugiados españoles a partir de mayo de 1939, las autoridades provenientes de la Revolución mexicana tuvieron que transformar sus discursos acerca de lo español. La hispanofobia, construida desde los sectores liberales del México revolucionario, que habían encontrado en la demonización de lo español un elemento esencial en la configuración del imaginario nacional mexicano, debía ser matizada $^{7}$. Así, en el nuevo discurso, los que llegaban a México representaban todo lo opuesto al español de antes. Los republicanos no iban a México a enriquecerse, sino para aportar sus conocimientos y su experiencia, aquella que la España atrasada y conservadora les había impedido poner en marcha en la madre patria. En todo ese proceso de modificación del discurso, el general Lázaro Cárdenas se implicó de forma directa, llevando personalmente muchos de los asuntos concernientes a la situación española ${ }^{8}$. A su altura estuvieron no pocos diplomáticos y funcionarios mexicanos, a pesar de la fuerte contestación interna que ese apoyo recibía por una parte importante de la sociedad mexicana ${ }^{9}$. Destacados intelectuales conservadores y el mundo católico azuzaron a la opinión pública con importantes críticas hacia las políticas del gobierno de Cárdenas, incluyendo en sus reproches también su política internacional, especialmente en lo concerniente a España.

Más allá de las simpatías existentes y las coincidencias ideológicas entre el gobierno cardenista y algunos de los protagonistas políticos de la II Repú-

7 Salazar, 2006.

8 Véase la carta de Lázaro Cárdenas a Isidro Fabela, 17 de febrero de 1937, Archivo Isidro Fabela, México DF, IF/II.4-077: 7, donde el presidente mexicano fija los márgenes de actuación en los que Fabela puede moverse en su defensa de la República española. Véase también Mateos, 2005.

9 Matesanz, 1999. 
blica española, la defensa de la legalidad republicana debe ser inscrita en el proceso de afirmación internacional del México posrevolucionario en los años treinta ${ }^{10}$. México buscaba su afianzamiento a través del respeto escrupuloso de la legalidad internacional, siguiendo la doctrina formulada por Genaro Estrada, canciller mexicano en los primeros años treinta y posteriormente embajador en España. La conocida como «doctrina Estrada», inspirada a su vez en la «doctrina Carranza», venía a defender la plena soberanía de los países y la no injerencia en sus asuntos internos a menos que fuese violentada por potencias extranjeras. El gobierno mexicano no reconocía gobiernos, simplemente mantenía, o no, relaciones bilaterales, evitando así la intromisión en la política nacional. Una doctrina ideada por México para afianzar una posición defensiva con respecto a su voraz vecino del norte. La decisión del presidente Cárdenas de la nacionalización de las empresas petrolíferas en marzo de 1938, y las tensiones diplomáticas que generó aquella medida fueron también la base de la necesidad de la afirmación internacional de México como país independiente y soberano ${ }^{11}$. Con la recepción de los españoles, pero también de otros exiliados como León Trotsky, México inauguraba una tradición como país solidario, país de acogida de exiliados y refugio de disidentes, imagen que se ha prolongado en el tiempo ${ }^{12}$.

Fueron muchos los quebraderos de cabeza que la acomodación de los exiliados españoles generó a las autoridades mexicanas, incluso antes de la llegada masiva. Las divisiones internas en que estaban sumidos los partidos políticos españoles generaron una fuerte confusión en los políticos mexicanos, llegando a tomar algunas decisiones un tanto difíciles de explicar. El golpe de Estado protagonizado por la Junta de Defensa de Madrid en marzo de 1939 contribuyó definitivamente a este estado de cosas. Así, el gobierno cardenista desconoció al gobierno legítimo de Juan Negrín, cancelando de facto las relaciones con la España republicana hasta su reconstitución institucional en el exilio en agosto de 1945, contradiciendo su propia doctrina internacional. Es necesario resaltar esta realidad, no siempre bien recogida por la historiografía del exilio. Durante los seis años que duró la II Guerra Mundial, México no mantuvo relaciones diplomáticas ni con la España franquista ni con la España del exilio. La embajada republicana en México fue clausurada y las relaciones quedaron anuladas. De esta manera, las autoridades republicanas permanecieron supeditadas a un diálogo donde la empatía personal jugó un papel preponderante en el acceso a los dirigentes mexicanos. Sin el reconocimiento

\footnotetext{
10 Ojeda Gómez, 1986.

11 Para un acercamiento al Cardenismo Medin, 1973. Gilly, 1994.

12 Yankelevich, 2002. González Gómez y Díaz Sánchez, 2008.
} 
unánime de la existencia del gobierno en el exilio y con la división creciente entre los distintos grupos que conformaban el difícil mosaico de los refugiados, los interlocutores se multiplicaron. En segundo lugar, la gestión del cargamento del yate Vita, entregado indebidamente a Indalecio Prieto por las autoridades mexicanas y que terminó por fracturar definitivamente las relaciones de las distintas organizaciones políticas españolas en el exilio, dando lugar a la duplicidad de instituciones de ayuda a los refugiados, que causaron acusaciones mutuas de favoritismos y uso sectario de los recursos ${ }^{13}$.

Hubo otros factores que generaron importantes conflictos a los dirigentes mexicanos como los problemas para acomodar laboralmente a los exiliados, dentro de un marco legal ciertamente restrictivo para el trabajo de extranjeros, frutos del nacionalismo triunfante en la Revolución Mexicana. A pesar de los intentos de la propaganda presidencial de hacer pasar a los exiliados como intelectuales, la mayoría de ellos eran obreros, profesionales liberales o campesinos, que necesitaban urgentemente encontrar un modo de subsistir. El apoyo decidido a la llegada de los exiliados de Vicente Lombardo Toledano, secretario general de la Confederación de Trabajadores Mexicanos, no impidió las protestas por parte de algunos sectores del obrerismo mexicano contra lo que consideraban la llegada de competencia foránea. «La Federación Sindicalista de obreros, campesinos y similares del Estado de Tlaxcala» emitió un manifiesto a la nación criticando la decisión de recibir a los refugiados españoles. Ondeando el discurso más nacionalista, realizaron una defensa de los intereses patrios frente a los excombatientes españoles, recordando el proceso de independencia iniciado en 1810. Reivindicando la defensa del proletariado mundial, pedían especial atención para los proletarios mexicanos frente a los extranjeros, en especial los proletarios españoles, hermanos de nación de los «indeseables españoles» que tan mal trataban a los mexicanos ${ }^{14}$. Detrás de esas protestas latía la tensión entre la CTM y Confederación Regional Obrera Mexicana que utilizaron el exilio como arma arrojadiza dentro de la política interna.

A las protestas obreras hay que sumar las manifestaciones de sectores de los comerciantes que rechazaban también la llegada de los españoles ${ }^{15}$. Ese

\footnotetext{
13 Hoyos Puente, 2011: 117-136.

14 Manifiesto de la Federación Sindicalista de obreros, campesinos y similares del Estado de Tlaxcala, 19 de julio de 1939, Archivo General de la Nación, México DF (AGN), fondo IPS, caja 315, exp. 10.

15 En el Archivo General de la Nación de México podemos consultar correspondencia de organizaciones mexicanas que protestan ante el presidente de la República por las manifestaciones organizadas por compatriotas mexicanos contra los españoles, como las dirigidas por
} 
estado de creciente crispación de la sociedad mexicana contribuyó a que la Oficina de Investigaciones Políticas y Sociales, dependiente de la presidencia de la República, dedicase especiales esfuerzos a conocer la dinámica interna de los exiliados y de sus organizaciones, infiltrando agentes de información. Estos agentes emitían informes puntuales de las actuaciones de los exiliados españoles y constataban su creciente división interna ${ }^{16}$. También a través de los informes podemos comprobar como la administración mexicana se encontraba dividida ante la llegada de los españoles y la política de hospitalidad desplegada por el presidente Cárdenas. Las opiniones emitidas por algunos inspectores distan mucho de mostrar simpatía alguna hacia los exiliados ${ }^{17}$. A pesar de este estado de cosas, Lázaro Cárdenas continuó impulsando la solidaridad hacia los exiliados al facilitar a los españoles que lo solicitasen la nacionalidad mexicana antes de finalizar su mandato en 1940.

Con su salida de la presidencia y la elección de un sucesor conservador como era Manuel Ávila Camacho, se abría un periodo de incertidumbres para los exiliados españoles en México ${ }^{18}$. Dirigentes como Indalecio Prieto, que habían gozado de un alto grado de confianza con el presidente Cárdenas, consideraban la elección de Ávila Camacho como un motivo de preocupación para el destino de los republicanos españoles allí exiliados. La decisión de Cárdenas de desplazar Francisco J. Mújica, uno de sus más estrechos colaboradores, y favorito para su sucesión entre el sector más progresista del gobierno mexicano, perjudicó notablemente a los exiliados españoles. Mújica defendió activamente durante la presidencia de Cárdenas la llegada de los españoles como un gran activo para la sociedad mexicana, combatió la visión maniquea y reduccionista que los equiparaba con «rojos» peligrosos que llegaban a México para seguir combatiendo, incluso militarmente, los valores conservadores ${ }^{19}$. Mújica representaba la continuidad de la política cardenista, con un amplio apoyo entre los sectores populares. Sin embargo no fue suficiente para contrarrestar los efectos de los partidarios de la consolidación de los logros, más que en la profundización de los mismos. Con Cárdenas la política social había tocado techo y con Ávila Camacho llegaba el tiempo de la institucionalización progresiva del régimen.

la Unión de Comerciantes Mexicanos de Veracruz en agosto de 1939. Véase AGN, México, fondo IPS, caja 315, exp. 10.

16 Informe dirigido a Cipriano Arriola, 8 de julio de 1939, AGN, México, fondo IPS, caja 315, exp. 10,

17 Informe del Inspector PS-15 a Cipriano Arriola, 15 de julio de 1939, AGN, México, fondo IPS, caja 81, exp. 4, p. 85.

18 Mateos, 2004: 405-443.

19 Moctezuma Barragán, 2001: 507ss. 
Durante su sexenio presidencial, las relaciones con los exiliados fueron menos fluidas y en algunas ocasiones hubo que recurrir a la intermediación de Cárdenas. Como bien ha documentado Abdón Mateos, las presiones internacionales, provenientes de Estados Unidos, fueron intensas para que México iniciara relaciones diplomáticas con la España de la dictadura. Lo cierto es que algunas de las iniciativas puestas en marcha por el presidente Cárdenas como La Casa de España, creada en 1938 para la recepción de profesores universitarios convertida ya en El Colegio de México, estuvo a punto de desaparecer en 1942 tras la reducción de la asignación presupuestaria de 350.000 pesos anuales a 200.000 por decisión presidencial ${ }^{20}$. Cárdenas había creado una excepcionalidad legal manifiesta en todo lo referente a los exiliados españoles, como fue la posibilidad de la creación de instituciones educativas privadas, bajo supervisión de la Secretaría de Instrucción Pública, pero con una cierta libertad de movimientos en un momento en que el Estado mexicano apostaba por la educación socialista. Aquella situación debía ser gestionada por un presidente no tan afín a los exiliados españoles y con una administración que viraba lenta, pero irreversiblemente, hacia un proceso de derechización política.

Ávila Camacho dio un impulso a las relaciones con los empresarios de la antigua colonia española que eran partidarios de reiniciar relaciones diplomáticas y comerciales, con la «Madre Patria». El nuevo presidente permitía que en el Casino Español, centro de sociabilidad por antonomasia de la colonia de antiguos emigrantes, se exhibieran retratos de Franco y banderas rojigualdas con el águila imperial, asistiendo incluso a uno de sus banquetes en junio de 1941. Además, su hermano Maximino, con estrechas conexiones económicas con la colonia española, se convirtió en el principal defensor de la reanudación de las relaciones diplomáticas con la dictadura. La presencia de importantes representantes profranquistas en el entorno más cercano del presidente mexicano suponía un notable cambio con respecto al sexenio del general Cárdenas. Así, el presidente Ávila Camacho recibía presiones en sentido opuesto, por un lado por parte de la intelectualidad mexicana prorepublicana, y por otro de los empresarios mexicanos y españoles que veían la posibilidad de hacer negocios con España. De este modo, se fue forjando bajo su mandato un difícil equilibrio entre el mantenimiento del desconocimiento diplomático hacia la España de la dictadura y la permisividad del establecimiento de relaciones oficiosas ${ }^{21}$.

\footnotetext{
20 Lida y Matesanz, 1990: 67.

21 Lida, 2001.
} 
Como nos ha mostrado Ricardo Pérez Montfort, la dictadura franquista fue buscando modos de acercamiento a la república mexicana, no siempre acertados, en la pretensión de erradicar uno de los principales emplazamiento de apoyo a los republicanos ${ }^{22}$. Desde Madrid, las autoridades de la naciente dictadura emprendieron una campaña para barrer del mapa todo resto de los republicanos como la desplegada en la Francia de Vichy. En ese sentido, la cobertura legal que México había otorgado a destacados dirigentes y cuadros medios de la República, y su negativa a establecer relaciones diplomáticas, supuso un fuerte revés para la diplomacia franquista, que no se resignaba a perder preeminencia en sus antiguas colonias. Su principal obstáculo para facilitar el entendimiento con las autoridades mexicanas fue la ausencia de una política hábil y realista. Desde un discurso agresivo, basado en la idea de recobrar el Imperio y recuperar para España el papel de cabeza de la Hispanidad trataron de realizar acercamientos. Para ello, utilizaron la cobertura de la embajada portuguesa en México para tratar de introducir representantes oficiosos, con el fin de encontrar interlocutores dentro de la vida política mexicana. Sin embargo, el discurso agresivo del imperio articulado y difundido por el Consejo de la Hispanidad, no era el mejor modo de acercarse al México posrevolucionario ${ }^{23}$.

A pesar de todo, durante el sexenio de Ávila Camacho, México no estableció relaciones con la dictadura franquista, ni siquiera tras el escándalo que suscitó en México la intervención de la Junta de Auxilio a los Refugiados Españoles, en noviembre de 1942, debido a la gestión dudosa realizada por el entorno de Indalecio Prieto ${ }^{24}$. El escándalo surgió cuando se descubrió que Prieto estaba enviando importantes cantidades con destino a Nueva York sin informar a las autoridades mexicanas. La intervención suponía una desautorización en toda regla para los republicanos, lo que animó a las autoridades franquistas a enviar un representante oficioso a México en 1944. Luis García Guijarro fue comandado a tratar de restablecer, como primer paso, las relaciones comerciales entre ambos países ${ }^{25}$.

La actitud del presidente Ávila Camacho fue mantener la situación como estaba, en un momento en el que los últimos meses de la II Guerra Mundial marcaban las relaciones diplomáticas mundiales. México había participado en la Guerra Mundial y no parecía adecuado relacionarse con un país tan identificado con las potencias del Eje, que económicamente tenía tan poco que

22 Pérez Montfort, 1992; 2001: 61-119.

23 Pardo, 1995. Pérez Montfort, 2001: 61-119.

24 Para esta cuestión resulta imprescindible el trabajo de Herrerín, 2007.

25 Escudero, 1990: 302. 
ofrecer. Además, México continuaba tratando de afianzar su propia personalidad diplomática en el concierto internacional. En febrero de 1945 se celebraba en la capital mexicana la Conferencia de Chapultepec, que buscaba un reequilibrio internacional en las relaciones interamericanas, con motivo del final de la II Guerra Mundial, tratando de alcanzar la acción conjunta y solidaria de los países americanos en un nuevo escenario internacional, en defensa de la soberanía de cada Estado. Conocida es la actuación del delegado mexicano Luis Quintanilla en la Conferencia de San Francisco a favor de la causa republicana.

Tras el triunfo de San Francisco, los republicanos españoles reunieron sus Cortes en agosto de 1945, gracias a la generosidad de Ávila Camacho que, permitiendo el evento y concediendo la extraterritorialidad temporal de la Casa de Cabildos del Zócalo de la ciudad de México, se convertía en un adalid de la defensa de la legalidad democrática española. Conocido también es el resultado de la reunión de las Cortes, la derrota de las tesis del presidente Negrín y la constitución del gobierno presidido por José Giral. Tras ese acto, el presidente mexicano restableció relaciones diplomáticas con la República española a la que entregó el dinero incautado a la JARE y la embajada española. México alcanzaba una notable relevancia al albergar en su territorio al gobierno republicano en el exilio que, tras la condena internacional a la dictadura franquista, parecía poder jugar un cierto papel. A pesar de la derrota de las tesis de Negrín, este se puso lealmente al servicio del gobierno. Como él la mayoría de los partidos democráticos, desde el ala reformista del PSOE hasta los representantes del nacionalismo catalán y vasco. El «gobierno de la Esperanza», como se conoció al ejecutivo presidido por Giral, parecía, al menos momentáneamente, alcanzar un grado notable de consenso.

Entre 1945 y 1946 el gobierno republicano en el exilio operó desde México con una intensa actividad diplomática dirigida por Giral con notables, aunque insuficientes, éxitos. Con el traslado del gobierno republicano a París en 1946, las relaciones bilaterales iniciaron una nueva fase. México mantenía, a través de la embajada española, relaciones con el gobierno republicano, cuidando de forma exquisita las formas y lenguajes diplomáticos, pero con un nivel menor de implicación. Pronto se demostró que las posibilidades de restitución del gobierno de la República en el exilio se iban a diluir totalmente. Desde París Giral consiguió, gracias a las sabias artes del ministro de Asuntos Exteriores, Fernando de los Ríos, la recomendación de la retirada de los embajadores de España aprobada por la ONU. Sin embargo, la ampliación del gobierno con la entrada de Santiago Carrillo como ministro sin cartera, causó la salida de los socialistas, promovida por Indalecio Prieto. 
Así, los exiliados fueron víctimas de sus divisiones internas y también del contexto internacional. Esa pérdida de opciones reales de los republicanos condicionó de alguna manera el giro de la política mexicana durante décadas, el mantenimiento del statu quo, pero con una política menos proactiva hacia la causa republicana, un proceso que coincidió con el giro definitivo de la institucionalización revolucionaria. La marcha del gobierno republicano a $\mathrm{Pa}$ rís suponía un cierto alivio para las autoridades mexicanas, fuese cual fuese el resultado de la causa republicana, su epicentro político ya no radicaba en su territorio. Mientras tanto, como ha sostenido Lorenzo Meyer, la política internacional se convirtió para México en un elemento de legitimación política a lo largo de la Guerra Fría ${ }^{26}$.

\section{LA CREACIÓN DEL PRI Y EL GIRO CONSERVADOR MEXICANO.}

El traslado del gobierno republicano en el exilio a París en 1946 coincidió con el cambio de sexenio y la creación en México del Partido Revolucionario Institucional. El traspaso del poder presidencial de Manuel Ávila Camacho a Miguel Alemán y la reconversión del Partido de la Revolución Mexicana en el PRI, escenificada el 18 de enero de 1946, evidenciaban la consolidación del sistema corporativista mexicano, que iba a hacer del partido el eje del funcionamiento del Estado. Los militares de la Revolución dejaban paso a una nueva generación de políticos, la mayoría con formación universitaria, que marcaron los destinos del país en las décadas siguientes. A pesar del aislamiento político al que las Naciones Unidas habían sometido a la dictadura franquista, en parte a instancias de México, el gobierno de Miguel Alemán mantuvo contactos discretos -según expresión mexicana, «bajita la mano»con los representantes oficiosos del régimen franquista. El 25 de septiembre de 1947, el representante oficioso de Franco en México Luis García Guijarro y Ramón Beteta, Secretario de Hacienda del gobierno mexicano, firmaron un acuerdo comercial ${ }^{27}$. Este hecho tiene una trascendencia política que sobrepasa el contenido del propio convenio, ya que suponía de facto el reconocimiento del agente de la dictadura como interlocutor válido. De este modo, las autoridades mexicanas realizaban un doble juego, en la medida en que tratando de mantener el status diplomático, buscaban las posibilidades de establecimiento de negocios. Así el gobierno de Miguel Alemán establecía un doble rasero que marcaría la nueva política del PRI hacia los exiliados. Por un lado,

\footnotetext{
26 Meyer, 2004: 95-117.

27 Escudero, 1990: 303.
} 
el mantenimiento de las relaciones diplomáticas y la defensa internacional fuera de las fronteras patrias. De hecho, solo unos meses antes, el presidente Alemán en un viaje a Estados Unidos había declarado públicamente, a preguntas de los periodistas norteamericanos, el firme compromiso del gobierno mexicano con el mantenimiento del desconocimiento del gobierno franquista $^{28}$. El inicio de relaciones comerciales con la dictadura, que venían a contentar las presiones internas de una parte muy significativa de la colonia de emigrantes españoles en México, posicionada desde el inicio de la Guerra Civil a favor de los sublevados y con los que el presidente Alemán compartía negocios.

Con la normalización de las relaciones comerciales se abrió una etapa en la que los contactos entre ambos países en todos los ámbitos, excepto en el plano estrictamente diplomático, vivieron una cierta normalización. Intercambios culturales y comerciales fueron incrementándose de forma progresiva.

La España franquista fue cambiando su política hacia América Latina. La dictadura había creado en 1945 el Instituto de Cultura Hispánica, que buscaba ser un puente con México y el resto de América latina. Alejados ya del discurso eminentemente fascista por motivos de supervivencia, el nuevo acercamiento se articuló desde un discurso católico que conectaba con intelectuales mexicanos como José Vasconcelos o Alfonso Junco. El catolicismo se convirtió en un nexo importante en aquellos tiempos. Con la derechización del PRI, la jerarquía católica mexicana recuperó un margen de maniobra perdido desde los tiempos de la Revolución. Ello facilitó el incremento de los contactos entre intelectuales católicos de ambos lados del Atlántico. Importante fue el viaje de Ángel Herrera Oria a México en 1947. Este influyente sacerdote montañés, fundador de la Asociación Católica Nacional de Propagandistas, desempeñó importantes trabajos «pseudo diplomáticos» a las órdenes del ministro de Asuntos Exteriores franquista Alberto Martín Artajo. Como resultado de aquellas gestiones, en 1948, el intelectual conservador mexicano José Fuentes Mares, participó en la Universidad Internacional Menéndez Pelayo en Santander, con un ciclo de conferencias sobre la Hispanidad que acabó siendo un alegato a favor de la unión de la «Raza» ${ }^{29}$.

El sexenio de Miguel Alemán representó un momento delicado en las relaciones con los exiliados españoles. La libertad de movimientos, aunque

28 En mayo de 1947 en su visita a Washington, Miguel Alemán sostuvo que no había posibilidad de cambios en las relaciones entre los dos países. Véase nota recogida en Matesanz, 1977: 385-386.

29 Las conferencias fueron publicadas por el Instituto de Cultura Hispánica, Fuentes Mares: 1949. 
vigilada, que los exiliados habían gozado hasta el momento se fue limitando con la aplicación del artículo treinta y tres de la Constitución mexicana, por la cual el Presidente podía expulsar a aquellos extranjeros que participasen en actividades de política interna ${ }^{30}$. Los exiliados aprendían así, de forma ejemplarizante, que tenían vetado opinar negativamente acerca de la vida política mexicana. A pesar del paso del tiempo, las cada vez menores expectativas de regreso a España y de la adopción de muchos de ellos de la nacionalidad mexicana, los exiliados en México eran una comunidad parcialmente integrada, con espacios abiertamente vedados.

Desde finales de 1948 se encontraba en México de forma discreta, un diplomático franquista de carrera, José Gallostra y Coello de Portugal. Su principal tarea era propiciar el clima necesario para restablecer las relaciones diplomáticas, una vez conseguida la firma del acuerdo comercial. Sin embargo, este católico fundamentalista realizó un importante labor de conexión con el Partido de Acción Nacional y los sinarquistas, despreciando al PRI. En alguno de sus informes remitidos al ministro de Asuntos Exteriores franquista se puede leer:

El PRI, que no es una organización comunista, es algo peor, es una organización de burgueses, los más de ellos capitalistas al amparo de la «revolución» que pretendiendo ser democráticos, ejercen la tiranía política del país; que diciéndose personas de orden atacan a la religión y mantienen la pugna con la Iglesia y que estafan al país. Es el partido de la masonería y la izquierda que no tiene el valor de ser comunista ${ }^{31}$.

A tenor de sus opiniones, no parece que las autoridades franquistas hubiesen escogido el mejor candidato para mejorar las relaciones con el gobierno mexicano. Sin embargo, su figura estuvo a punto de cambiar las relaciones entre España y México debido a un hecho fortuito. El 20 de febrero de 1950, José Gallostra fue asesinado en la ciudad de México por Salvador Freitas, un exiliado anarquista que trabajaba para él como informante acerca de las actividades de los republicanos, por un desacuerdo en el pago de sus honorarios. El asesinato de Gallostra fue difundido por la prensa española como un escándalo internacional y una prueba más de lo peligroso que eran los «rojos» españoles. $\mathrm{ABC}$ dedicó varias páginas en los días sucesivos para tratar de convencer a los dirigentes mexicanos de que era el momento de romper las

\footnotetext{
30 AGN, fondo IPS.

31 Archivo del Ministerio de Asuntos Exteriores, Madrid, leg. R 2314, exp. 9, citado en Pérez Montfort, 2001: 109.
} 
relaciones con el gobierno en el exilio ${ }^{32}$. Su velatorio se celebró por todo lo alto en el Casino Español. Aquella acción irritó a las autoridades mexicanas sobremanera ya que, a pesar de carecer de status diplomático, Gallostra se encontraba en México con la autorización más o menos explícita del gobierno de Miguel Alemán, y su asesinato suponía una afrenta a la política interna mexicana.

$\mathrm{Su}$ muerte fue un hecho aislado de los grupos políticos del exilio, sin embargo, el revuelo organizado y la criminalización de todo el colectivo facilitaban la posibilidad de cancelar las relaciones con un gobierno en el exilio cada vez más debilitado, y con menos oportunidades de algún triunfo tras el inicio de la Guerra Fría ${ }^{33}$. Fue la documentación encontrada en el alojamiento de Gallostra lo que frenó todo cambio. En el registro de su habitación, la policía mexicana halló los cuadernos de notas de Gallostra, base de sus informes, donde ridiculizaba al PRI, al presidente Alemán y a los indios mexicanos. Los cuadernos de Gallostra salvaron a las instituciones republicanas, mientras la dictadura se iba incorporando progresivamente a las instituciones internacionales, con el apoyo decidido de los gobiernos de los Estados Unidos, que habían encontrado en Franco un aliado útil contra el expansionismo comunista en una zona estratégica fundamental. El progresivo cambio de actitud de Estados Unidos hacia la dictadura franquista y el inicio de la política de bloques de la Guerra Fría, crearon un escenario del que México quiso permanecer al margen. En su afán por mantener distancias con la política de los Estados Unidos, continuar desconociendo la dictadura franquista en el terreno diplomático podía seguir dando sus frutos en la construcción de una imagen independiente. Mientras, en su política interna, el PRI fue apretando las tuercas cada vez más a los sectores a su izquierda, consagrando una tendencia creciente en las próximas décadas.

Mientras, las crisis de los gobiernos republicanos se sucedían en París ${ }^{34}$. La dimisión de José Giral, ante el abandono de los socialistas del ejecutivo en 1947, fue atajada de forma precaria con los gabinetes del socialista Rodolfo Llopis y más tarde de los gobiernos del republicano Álvaro de Albornoz ${ }^{35}$. La estructura sobredimensionada del gabinete Giral, agotó los fondos con los que las instituciones republicanas contaban. Así a la altura de 1949 el gobierno republicano en el exilio apenas tenía para subsistir. En 1950, Álvaro de

32 Cobarde asesinato del ministro de España, señor Gallostra, ABC, (Madrid, 24 de febrero de 1950): 4.

33 Para un acercamiento a esta cuestión véase Yuste de Paz, 2005.

34 Lemus, 2010.

35 Cabeza Sánchez Albornoz, 1997. Sánchez Cervelló, 2011. 
Albornoz trató de gestionar el regreso de las instituciones republicanas a México, sin obtener la autorización por parte de las autoridades mexicanas ${ }^{36}$. Buscaba el veterano político asturiano recuperar la protección de México y de la importante comunidad de exiliados allí afincada. Sin embargo, el tiempo político y los protagonistas de la vida política mexicana ponían cada vez mayor distancia con las instituciones republicanas, manteniendo las exquisitas formas de la diplomacia mexicana.

Sin duda, el sexenio de Miguel Alemán representó el momento más crítico para las relaciones políticas con las instituciones republicanas. Por un lado, las divisiones que habían marcado la vida política del exilio republicano desde su inicio habían debilitado sobremanera el apoyo interno de las instituciones $^{37}$. Por otro lado, su falta de recursos económicos pero, sobre todo, la falta de apoyos internacionales sólidos, obligaban a los dirigentes republicanos a apoyarse cada vez más en México.

La sustitución de Álvaro de Albornoz por Félix Gordón Ordás en la presidencia del consejo de Ministros en 1951, ponía el destino de las instituciones republicanas en manos de uno de los políticos españoles que mejor conocía la política mexicana, desde sus tiempos de embajador de la República durante la Guerra Civil. A pesar de trasladar su residencia a París, Gordón Ordás viajó constantemente a México, donde trató de conseguir la autorización para realizar una nueva convocatoria de Cortes. Pero esta vez, México negó su apoyo a la celebración de dicha reunión. México solo estaba dispuesto a fijar una cuantía mensual para contribuir al sostenimiento de las instituciones republicanas en París ${ }^{38}$.

Para las autoridades mexicanas, la cuestión española había llegado a un punto muerto. Con las relaciones comerciales restablecidas con la España real y las comunicaciones abiertas, las relaciones diplomáticas con la dictadura no resultaban indispensables. A cambio, el mantenimiento de un apoyo sin compromisos hacia los republicanos contribuía a dar prestigio interior y exterior a un México cada vez más derechizado. México experimentaba un crecimiento económico espectacular gracias a la industrialización y al desarrollo de las infraestructuras, y un floreciente desarrollo cultural del que se beneficiaba unos pocos sectores de la sociedad, entre ellos los exiliados. Este estado de cosas convivía con unos índices de corrupción política alarmantes. Los políticos mexicanos del PRI trataban de proyectar la idea de que habían heredado lo mejor de las culturas políticas reformistas de la II República española. De

\footnotetext{
36 Cabeza Sánchez Albornoz, 1997: 201.

37 Hoyos Puente, 2010: 235-262.

38 Gordón Ordás, 1969.
} 
este modo, los dirigentes del PRI mantenían también una cierta vinculación simbólica con los tiempos del cardenismo y la solidaridad con España, a pesar del giro político, económico y social establecido. El PRI de los años cincuenta no era ya el partido de Cárdenas, convertido en un elemento simbólico, sino que culminaba su proceso de oligarquización y monopolización del poder a través de muy diversas redes clientelares y corporativas, que hicieron de México una particular dictadura de partido, aunque formalmente continuase siendo una república presidencialista.

Así, el México oficial mantenía las formas a través de unas relaciones cordiales y protocolarias con la República española, pero nada más. Los presidentes mexicanos siempre estaban representados por algún alto funcionario en los actos conmemorativos de la República, y el embajador de España invitado a la tribuna diplomática en los discursos anuales del Presidente ante el Congreso mexicano. La retórica discursiva mantenida por los gobernantes mexicanos se fundamentaba en el respeto a la ya tradicional doctrina mexicana en política internacional. La consolidación del franquismo en el escenario internacional y el progresivo deterioro de la posición del gobierno republicano en el exilio no favorecían la intensificación del apoyo mexicano a las opciones democráticas en España. A su vez, la dictadura franquista fue perdiendo interés por México, en la medida que estaba consiguiendo el acercamiento a países de mayor relevancia internacional, especialmente con los Estados Unidos, así como su afianzamiento en América Latina a través de la Argentina de Perón.

Félix Gordón Ordás trató de muy diferentes maneras recuperar el espacio perdido en México. Así, promovió la organización de conmemoraciones y eventos para influir en las autoridades mexicanas, pero también en los propios exiliados. En 1953 propuso la creación de un Consejo Delegado de la República en México ${ }^{39}$. Finalmente el proyecto se materializó aunque modificado, mediante la puesta en marcha en 1954 del denominado Consejo de Defensa de la Republica Española con sede en México, creado por decreto presidencial ${ }^{40}$. Según su reglamento, sus funciones eran mantener la representación institucional de la República en colaboración con la Embajada en México. Compuesto por un presidente, tres vicepresidentes, un secretario general, un tesorero y cinco vocales, su trabajo debía también centrarse en aunar esfuerzos y recuperar predicamento dentro de la comunidad exiliada

39 Propuesta presentada por el Sr. Robles Macia al Comité Ejecutivo Nacional de Unión Republicana de México y sometido a debate de la Asamblea General del Partido el 16 de junio de 1953, Fundación Universitaria Española, Madrid, fondo México, 66-2.

40 Alonso García, 2004: 353. 
en México ${ }^{41}$. Un órgano más que tampoco consiguió ningún resultado reseñable. Muchos de los refugiados, distanciados cada vez más de las organizaciones políticas del exilio, habían emprendido un proceso de adaptación a un México lleno de oportunidades. Desde muchos puntos de vista, se produjo un cierto proceso de "gachupinización» en los comportamientos de ciertos sectores del exilio, derivados en parte de un ascenso social en ocasiones vertiginoso. Así, a pesar de mantener un discurso que recordaba su condición de refugiados, su nivel de politización y compromiso cotidiano fue decayendo, mientras que afianzaban sus relaciones con la casta política asociada al PRI, como en los tiempos del porfiriato hicieran muchos emigrantes económicos españoles ${ }^{42}$.

El sucesor de Miguel Alemán en la presidencia de México, Adolfo Ruiz Cortines, tampoco mostró intenciones de establecer ningún cambio en su política hacia los republicanos españoles. Centrado en el desarrollo del país, Ruiz Cortines encontraba el caso español muy alejado de sus preocupaciones. En un intento a la desesperada por devolver visibilidad a las instituciones republicanas en México, el presidente Gordón Ordás ideó un homenaje multitudinario a Lázaro Cárdenas. Era la figura incontestable, representaba el padre del México moderno y era para los exiliados un santo laico. Si algo podía movilizar masivamente a los exiliados era un homenaje a Cárdenas. Así, el 14 de abril de 1957, coincidiendo con la conmemoración de la República Española, las instituciones republicanas organizaron un gran acto en el Cine Florida de México. Siete mil personas del exilio y de la sociedad mexicana asistieron al evento. Con discursos del encargado de negocios de la embajada republicana en México, Manuel Martínez Feduchy, la adhesión de Martínez Barrio desde París y el esperado discurso de Cárdenas que renovó su compromiso y afecto a la República española. El acto finalizó con un gran banquete de homenaje que se convirtió en uno de los actos sociales más importantes del exilio republicano de toda la década de los cincuenta $^{43}$. La utilización del prestigio personal de Cárdenas a favor de los refugiados tenía una doble dirección. Reconocido internacionalmente y sobre todo dentro del propio entramado del México priista, su figura podía ser el revulsivo necesa-

41 El reglamento se conserva la Fundación Pablo Iglesias, Madrid. Archivo de Luis Jiménez de Asúa, 401-37.

42 En este sentido véase el sugerente trabajo Faber, 2002.

43 De aquel acto se editó un extenso folleto donde se recoge ampliamente el desarrollo del importante acontecimiento y la historia del exilio en México. Véase Homenaje de la emigración española al General Lázaro Cárdenas, México, Embajada de España, 1957, Biblioteca Daniel Cosío Villegas de El Colegio de México. Gordón Ordás resalta la importancia de este acto conmemorativo en sus memorias, Gordón Ordás, 1970: 805. 
rio para cambiar la actitud. Cárdenas era por entonces una figura totémica, intocable e incuestionable, con gran predicamento entre los sectores progresistas de la sociedad mexicana, pero perteneciente a un tiempo político ya agotado.

A lo largo de la década de los cincuenta del siglo pasado, las dificultades económicas para el sostenimiento del gobierno republicano en el exilio no hicieron más que agravarse, a pesar de su cada vez más reducida estructura. Gordón Ordás tuvo que solicitar de forma desesperada el pago de una vieja deuda contraída por parte del gobierno mexicano con las autoridades republicanas por la compra de material militar en los momentos finales de la Guerra Civil española. Una deuda que las autoridades mexicanas abonaban de forma mensual. En 1958 Gordón Ordás se dirigió al nuevo presidente mexicano Adolfo López Mateos, el día siguiente de su nombramiento, para informarle de la delicada situación en que se encontraba el gobierno de la República en el exilio ${ }^{44}$. Doce días más tarde era recibido por el presidente López Mateos que renovaba el compromiso de México con la República española. De aquel encuentro Gordón obtuvo el compromiso de que bajo su mandato no se produciría un cambio en las relaciones con España. López Mateos consideraba que con una monarquía heredera de Franco difícilmente iban a cambiar las relaciones entre ambos países a menos que existiesen garantías de las libertades de los españoles ${ }^{45}$.

El importante compromiso de López Mateos no implicaba una solución para la cuestión económica. Eran los difíciles años que Virgilio Botella Pastor describió en sus memorias sobre las penosas experiencias que vivieron los ministros de la República en París, derivadas de la falta de recursos económicos:

Fue la época en la que en la casa de Valera llegaron a faltar las sábanas, por ejemplo; en la que José Maldonado, que sería el último Presidente de la República en el exilio, vivía en un pequeño apartamento interior, triste y lóbrego como una mazmorra $^{46}$.

El sexenio de Adolfo López Mateos estuvo marcado en el terreno internacional por el triunfo de la Revolución Cubana y la posterior crisis diplomática internacional que desencadenó ${ }^{47}$. México había sido anfitrión del exilio de

44 Carta de Gordón Ordás a Adolfo López Mateos, fechada en México el 2 de diciembre de 1958, Fundación Universitaria Española, Madrid, fondo México.

45 Gordón Ordás, 1970: 869.

46 Botella Pastor, 2002: 206.

47 Rodríguez de Magis, 1965: 121-135. 
Fidel Castro anterior a la Revolución y desde allí ideó y organizó la expedición del Granma, con frecuentes visitas al Ateneo español de México ${ }^{48}$. La cancillería mexicana esgrimió de nuevo su tradición diplomática para defender el mantenimiento de relaciones con la Cuba revolucionaria y marcar así su personalidad propia frente a los Estados Unidos. Así, en la reunión de la Organización de Estados Americanos, celebrada en julio de 1964 en Washington, los mexicanos defendieron su tradición de respeto a la libre autodeterminación y la soberanía interna, recordando su postura inquebrantable hacia la República española ${ }^{49}$. Los Estados Unidos habían tratado de convencer a México que cambiara su actitud hacia la dictadura española antes y después del viaje de Eisenhower a España en 1959. Precisamente ese viaje causó un cierto resurgir del exilio republicano que, desde México, inició importantes campañas de denuncia sobre aquella visita, recordando la represión continua de la dictadura hacia los ciudadanos españoles.

En ese clima de euforia franquista, el nuevo embajador oficioso de Franco en México, Manuel Oñós de Plandolit, inició la organización de un banquete conmemorativo del 18 de julio en el Casino Español. Oñós, con amplia experiencia diplomática en América Latina desde los años cuarenta, consideraba lo suficientemente consolidada la dictadura como para tratar de celebrar de forma pública y notoria, con invitación al cuerpo diplomático acreditado en México incluida, lo que años atrás se venía haciendo de forma discreta por los sectores de emigrantes españoles pro franquistas. La dictadura consideraba que la visita programada del presidente Eisenhower suponía un acto de legitimación incontestable en el concierto internacional, que influiría definitivamente en la actitud del gobierno mexicano. Ante la noticia del banquete, un grupo de jóvenes republicanos exiliados, asaltaron las oficinas de la embajada oficiosa, destruyéndolas casi por completo y anunciaron su intención de secuestrar a Oñós de Plandolit si persistía en su actitud de celebrar el 18 de julio. Las autoridades mexicanas, asustadas por la dimensión que estaba tomando la reacción de los exiliados, optaron por denegar el permiso para celebrar aquella reunión incómoda, no tanto por el hecho de su celebración, sino por la notoriedad que había alcanzado. De aquel pequeño éxito nació el Movimiento Español 1959, que fue tomando cuerpo para realizar nuevas acciones como las protestas contra la visita de Eisenhower a Franco en diciembre de ese mismo año ${ }^{50}$.

48 La estancia en México de Fidel Castro y sus relaciones con el exilio republicano español son un asunto todavía por estudiar con detenimiento.

49 Rodríguez de Magis, 1965: 134.

50 Aub, 1992. Aznar Soler, 2011:143-198. La declaración de Principios del Movimiento Español 1959, Ateneo Español de México, México, fondo Histórico, caja 45, leg. 441, exp. 1. 
En abril de 1960 dimitió de su cargo al frente del gobierno en el exilio Félix Gordón Ordás ante las desavenencias con el presidente de la República y compañero de partido Diego Martínez Barrio. Sus diferencias surgieron a raíz de unas declaraciones de Martínez Barrio defendiendo el uso de la violencia como instrumento legítimo para luchar contra la dictadura. Tras él, asumió la presidencia del gobierno en militar independiente Emilio Herrera. La muerte de Martínez Barrio el 1 de enero de 1962 en París, evidenciaba el agotamiento de unas instituciones superadas por las circunstancias y la realidad de los hechos ${ }^{51}$. A pesar de ello, Luis Jiménez de Asúa, desde Buenos Aires, ocupó la presidencia de la República en el exilio, que entró en un periodo de abierta inacción política.

Tras el sexenio de López Mateos, en 1964 le sucedió en la presidencia de México Gustavo Díaz Ordaz. A lo largo de su mandato, muy controvertido en política interior, Díaz Ordaz utilizó al exilio como elemento de legitimación interna, recurriendo a él de forma simbólica. Su presencia en el velatorio de León Felipe, figura ya mítica dentro del exilio, el 18 de septiembre de 1968, quería dar testimonio de la cercanía de la política mexicana con los exiliados españoles. La apropiación por parte de las autoridades mexicanas del poso democrático del exilio español, mientras trataba de ocultar su creciente represión interna, resulta a todas luces evidente. La contestación por parte de la izquierda mexicana, inscrita en el contexto internacional de los movimientos estudiantiles de los años sesenta, pero con derivaciones propias de gran calado, originaron un proceso de represión y persecución política cuyo hecho más conocido fue sin duda la brutal represión de octubre de 1968 en la Plaza de Tlatelolco ${ }^{52}$. Aquellos hechos dramáticos ponían en evidencia las profundas contradicciones entre discurso, imaginario y prácticas políticas, de un régimen convertido en dictadura de partido, incapaz de gestionar pacíficamente ningún tipo de disidencia u oposición. Un acto de aquellas características, que chocaba con los principios básicos que siempre habían defendido los exiliados españoles, y que sin embargo no despertó respuesta ninguna por parte de aquellas organizaciones que, si bien habían prometido no inmiscuirse en asuntos internos, a esas alturas estaban formadas por refugiados que contaban con la nacionalidad mexicana de pleno derecho.

El terrorismo de Estado y la represión se habían asentado dentro del régimen priista, mientras que sus discursos oficiales mantenían la defensa de los derechos humanos en el ámbito internacional durante toda la década de los setenta, abriendo nuevamente sus fronteras a la oleada de exiliados proceden-

51 Sánchez Cervelló, 2011.

52 Condés Lara, 2007. 
tes de las dictaduras del Cono Sur de América Latina, durante la presidencia de Luis Echeverría ${ }^{53}$. Echeverría, quien fuera secretario de Gobernación durante los sucesos de 1968, convirtió su sexenio en el paradigma de la defensa de los exiliados chilenos, uruguayos y argentinos. Sucesos de represión contra manifestantes como la matanza del Corpus Cristi en junio de 1971 a manos de paramilitares, contribuían a enfangar la situación interna del país, creando una mayor oposición al régimen. Echeverría trató por todos los medios de limpiar su imagen, recurriendo a discursos y gestos que buscaban relacionar su figura con la del presidente Cárdenas. También la necesidad de prestigiar en el interior del país la política del PRI llevó a tratar de rememorar los tiempos del general Cárdenas, que había fallecido en octubre de 1970, causando una auténtica conmoción nacional.

Echeverría buscaba la legitimación exterior de México, mediante una vigorización del papel del presidente en política internacional, para silenciar los puntos más oscuros de su política interior desde los tiempos de octubre de 1968 y la matanza de Tlatelolco. La construcción de una imagen de estadista internacional, defensor de los derechos humanos, y aplaudido por una parte de la izquierda latinoamericana. Echeverría trató de rodearse de referentes y símbolos de la izquierda, como hizo durante el viaje de Salvador Allende a México en 1972, que tuvo un recibimiento multitudinario por parte de la izquierda opositora a la política priista ${ }^{54}$. Dentro de aquella estrategia el apoyo a los exiliados españoles y latinoamericanos se convirtió en una pieza clave. Así, uno de los presidentes más odiados por la izquierda mexicana, era el salvador de la izquierda de muchos otros países latinoamericanos, convirtiéndose en uno de los ejemplos exponenciales de las contradicciones del sistema político mexicano.

Los republicanos españoles se beneficiaron de la vehemencia internacional de Luis Echeverría a la hora de defender las democracias y los derechos humanos $^{55}$. Luis Echeverría había cultivado desde su época de estudiante en la UNAM unas relaciones preferentes con el exilio republicano, lo que le había llevado incluso a crear una revista de apoyo a su causa ${ }^{56}$. A lo largo de su carrera política mantuvo siempre unas relaciones estrechas con los exiliados y a su llegada a Los Pinos, la política hacia las instituciones republicanas se

53 González Gómez y Díaz Sánchez, 2008. Yankelevich, 2009.

54 Mendoza, 1973.

55 Véase Sola Ayape, 2008: 139 s.

56 Luis Echeverría fue el director de México por España, boletín del comité de ayuda a la Juventud española, se puede consultar en la Fundación Pablo Iglesias, Madrid, signatura P. 2014. 
fortaleció. Este punto de inflexión en las relaciones bilaterales coincidió con la última renovación de las instituciones republicanas en el exilio.

La muerte de Luis Jiménez de Asúa en 1970, dejaba vacante de nuevo la presidencia de la República en el exilio. El veterano político de Izquierda Republicana, José Maldonado estaba llamado a ser el sucesor, atendiendo al complejo proceso de sustitución previsto en la Constitución republicana de 1931. Su llegada a la alta magistratura del Estado en el exilio y la sustitución de Claudio Sánchez Albornoz por Fernando Valera, supuso la revitalización de las instituciones republicanas, que habían vivido sus horas más bajas en manos de Jiménez de Asúa. Su escepticismo acerca de la utilidad del mantenimiento de aquella empresa había convertido a las instituciones republicanas en un ente muy diluido, más allá de su simbolismo. Gracias a Maldonado y Valera, vivieron las instituciones un impulso renovado, que consiguió devolver cierta visibilidad a la República española, gracias en buena medida al apoyo del presidente Echeverría. Motivos no faltaban para hacer este último esfuerzo, conscientes como eran que el tiempo del dictador, más temprano que tarde, debía acabarse. De esta manera, las instituciones republicanas vivían un cierto resurgimiento que alentaba al movimiento republicano en México. Esa revitalización se manifestó básicamente en actos y conmemoraciones. La desconexión de los republicanos con el interior era más que evidente y esa falta de arraigo hacía difícilmente viable sus posibilidades en la gestión de una etapa postdictadura. Con todo, los actos de conmemoración del 14 de abril resurgieron con gran fuerza en la década de los setenta ${ }^{57}$. Con motivo del cuarenta aniversario de la proclamación de la Segunda República, el Centro Republicano Español organizó nuevamente un gran evento donde el secretario de Gobernación mexicano, Mario Moya, en nombre del presidente Echeverría, volvía a renovar los votos de apoyo y reconocimiento de la República mexicana a la República española ${ }^{58}$. Esa actitud proactiva de Echeverría hacia las instituciones republicanas en el exilio era recogida por periódicos estadounidenses devolviendo visibilidad a la causa española ${ }^{59}$.

Mientras de forma pública y notoria se producía este acercamiento hacia la legalidad republicana, Echeverría mantuvo contactos con otras organizaciones políticas, también en el exilio, que habían dado por muertas hacía tiempo

57 El Centro Republicano Español de México acogió en 1970 un acto multitudinario donde las autoridades mexicanas se volcaron con los republicanos españoles. Véase el folleto editado por dicha institución. Existe copia en la Biblioteca de El Colegio de México.

58 Véase el folleto del XL aniversario que se conserva en el Ateneo Español de México.

59 "Mexico reassures Spanish Exiles", The Washington Post (Washington, 23 abril 1974): 12. 
las instituciones republicanas, volcados en una estrategia hacia el interior de España. Así, como señala Santiago Carrillo en sus memorias, el presidente Echeverría recibió al secretario general del PCE y facilitó reuniones con Jesús Reyes Heroles, presidente del PRI, y con su sobrino, el influyente Rodolfo Echeverría. De aquellas entrevistas, Santiago Carrillo consiguió un generoso donativo de cuatrocientos mil dólares para la financiación de las actividades del $\mathrm{PCE}^{60}$. El dirigente socialista Felipe González también viajó a México en busca de apoyo y reconocimiento político, además de con la intención de sofocar la división interna que su ascenso al poder en la organización generó dentro del socialismo entre históricos y renovadores. Por tanto, el PRI mantenía una estrategia dual frente a los exiliados. Por un lado, mantenía su vinculación simbólica con las instituciones republicanas mientras, por otro, afianzaba y fortalecía la relación con los dirigentes políticos que estaban en mejores condiciones de afrontar un papel realmente influyente en los tiempos posteriores a la dictadura.

Los actos simbólicos se sucedieron en la década de los setenta, alcanzando una notable repercusión internacional. El New York Times recogía en 1974 los actos celebrados en México con motivo del 14 de abril y el homenaje realizado a la figura de los desaparecidos León Felipe y Lázaro Cárdenas ${ }^{61}$. Sin la presencia del presidente Echeverría esa visibilidad hubiese sido sin duda menor. A medida que las noticias sobre la salud del dictador hacían más evidente su inminente final, el presidente Echeverría iba aumentando su nivel de implicación pública hacia la causa republicana. Así, las últimas condenas a muerte decretadas por el franquismo, ejecutadas en septiembre de 1975, se convirtieron en un tema de gran importancia para Luis Echeverría, que trató de hacer de aquel execrable crimen un elemento medular a la hora de conseguir la condena internacional de la dictadura. Su discurso ante las Naciones Unidas de condena al franquismo, la campaña sostenida por los principales dirigentes del PRI, con su nuevo presidente Porfirio Muñoz Ledo a la cabeza, así como la ruptura de las comunicaciones con España, muestran la gran relevancia política que trató de darse a aquellos sucesos dramáticos ${ }^{62}$. Echeverría obligó al cierre de la oficina de la representación oficiosa de la dictadura en su país.

Las motivaciones que llevaron a Echeverría a iniciar una ofensiva internacional de aquellas características, buscando la condena del Consejo de Se-

\footnotetext{
60 Carrillo, 1993: 604.

61 "Franco's old foes gather in Mexico", The New York Times (New York, 15 abril 1974): 13.

62 Véase Cordero, 2005. Sola, 2008.
} 
guridad de la ONU y la expulsión de España de la organización internacional, tuvo claros fines propagandísticos. De hecho la declaración del boicot de México alcanzó una notable repercusión internacional ${ }^{63}$. Por un lado, como sostiene Inmaculada Cordero, Echeverría encontró en esta acción la ocasión para buscar la reconciliación con importantes sectores de la izquierda mexicana, vinculados emocionalmente con el exilio español, y alejados abiertamente del PRI por su brutal ejercicio de la represión interna. Por otro, Echeverría ansiaba el puesto de Secretario General de las Naciones Unidas como posible retiro tras la presidencia, en un momento en que su mandato iniciaba la recta final. Fuese cual fuese la motivación real, el hecho evidente es que la actitud de Echeverría dio notoriedad a las instituciones republicanas en el exilio.

En octubre de 1975 los republicanos se reunieron nuevamente para dar respuesta contundente a los últimos fusilamientos del franquismo. Ese acto contó con la presencia del presidente Luis Echeverría lo que dio al evento una especial relevancia ${ }^{64}$. Muy pocos días antes de la muerte del dictador en Madrid, los republicanos españoles organizaron otro gran acto de homenaje a México, con un claro espíritu de despedida, que también contó con la presencia de Luis Echeverría. Para aquella ocasión, Fernando Valera, a la sazón presidente del gobierno en el exilio, se trasladó desde París para participar en aquel homenaje que devolvía definitivamente a las instituciones republicanas un protagonismo perdido en los años sesenta. Las máximas autoridades del PRI escenificaban su afecto con la República española y su reconocimiento a los esfuerzos mantenidos, como la Numancia errante que resistía el irremediable paso del tiempo. Los discursos pronunciados resaltaban la dimensión nacional del legado de la República española, ejemplo de proyecto democrático y modernizador de un país atrasado, donde sus oligarquías impusieron a sangre y fuego sus privilegios. No faltaron las referencias al quijotismo del exilio y a la generosidad mexicana. En el discurso de Valera se puede comprobar la profunda desconexión que existía con la realidad interior. En aquel acto, celebrado el 9 de noviembre de 1975, también estuvo presente el primer ministro de Dinamarca, Anker Jorgensen que, de visita en México, quiso acompañar con su presencia a la legitimidad republicana. En su discurso, el

63 "Boycott of Spain urged by Mexico", The New York Times, (New York, 30 septiembre 1975): 7.

${ }_{64}$ El contenido de la reunión fue difundido mediante su correspondiente folleto con el título Por España, contra Franco, mensaje a los españoles con copia al resto de la opinión mundial, México DF, Centro Republicano Español, 1975. Ejemplar en el Archivo del Ateneo Español de México. 
presidente Echeverría realizó un reconocimiento expreso a todas las aportaciones que durante décadas los españoles habían entregado a México. México mantendría la hospitalidad a todos los que decidiesen no regresar a la España democrática, que seguirían siendo en México patriotas españoles y mexicanos por derecho propio ${ }^{65}$.

En ese clima de denuncia del régimen franquista, llegó la noticia del fallecimiento del octogenario dictador. Los veteranos exiliados que consiguieron sobrevivir a Franco experimentaron una mezcla de sensaciones, desde el júbilo a la incertidumbre ante el incierto futuro de España. La rápida instauración de la monarquía, heredera de la dictadura en la figura de Juan Carlos de Borbón, provocó una fuerte consternación en los republicanos liberales que rechazaron de plano esa vía continuista. Un sucesor de Franco a título de Rey era insostenible a ojos de los republicanos que apostaban por una ruptura democrática, que contase con ellos ${ }^{66}$. Mientras, las autoridades mexicanas moderaron su discurso y adoptaron una postura prudente ante los cambios políticos en España. Echeverría revocó la suspensión de los contactos comerciales tras la muerte de Franco. La desaparición del dictador abría un nuevo escenario donde la prudencia y la expectación fueron las características más evidentes de la política mexicana hacia España.

En esos momentos, México se adentraba en un delicado proceso interno de sucesión presidencial en un clima sumamente complejo. La elección de José López Portillo como sucesor de Echeverría y la no concurrencia electoral de ningún candidato del PAN deslegitimaba un proceso electoral en el que nuevamente el PRI arrasó, con unos datos abrumadores que ponían de manifiesto lo fraudulento del sistema. A medida que la Transición política avanzaba en España, la sociedad mexicana se volvió más expectante ante ese proceso de cambio político, como demuestra la cantidad de referencias publicadas al respecto en distintos medios de comunicación mexicanos. El apoyo decidido a la República de Echeverría se diluía en la presidencia de su sucesor José López Portillo. Desde Estados Unidos, se esperaba con expectación cual serían los siguientes pasos del gobierno mexicano respecto a la evolución de la Transición española ${ }^{67}$. México veía en el proceso de reformas emprendido en España una posible solución a su propia situación interna. Una apertura

65 Véase el folleto "Banquete al señor Presidente Luis Echeverría Álvarez y a su distinguida esposa”, Centro Republicano Español, México DF, 1975, Ateneo Español de México.

66 Marichal, "La legitimidad republicana. No le hace falta rey a la nueva España", República Española, ARDE, 23 (México, 14 abril de 1976): 4 y 5.

67 "Mexico debates new ties with Spain", The New York Times, (New York, 11 junio 1976): 12 . 
para salvar su propio régimen. En ese clima, México abordó su propio proceso de reforma política y electoral ideada por Jesús Reyes Heroles ${ }^{68}$.

José López Portillo inició el acercamiento necesario para reanudar las relaciones con la España real. Las autoridades republicanas radicadas en París, no recibieron con agrado aquella noticia a pesar del mantenimiento de las formas ${ }^{69}$. Los viejos republicanos carecían de fuerza y presencia organizada en el interior y habían sido abandonados por el resto de los partidos de izquierda. Por todo ello debían jugar todo su peso político en el exilio, lo cual limitaba de forma ostensible su margen de maniobra. A la altura de febrero de 1977, los republicanos de Acción Republicana Democrática Española continuaban manteniendo que la monarquía de Juan Carlos no duraría a pesar de los logros alcanzados. Señalaban a Cataluña como protagonista de la lucha republicana ${ }^{70}$. Un mes después, ante la convocatoria de elecciones en España, México tomó la decisión de cancelar las relaciones diplomáticas que mantenían con la República española en el exilio, a pesar de que ni republicanos ni comunistas habían sido legalizados todavía en España. Ante el inminente cambio, las autoridades mexicanas rompían su propio compromiso de fidelidad a la causa republicana, en aras de obtener una posición ventajosa en la nueva situación de España. Los ancianos republicanos aceptaron con resignación aquella decisión y participaron en el acto diplomático celebrado el 18 de marzo de 197771. Los republicanos recibieron una compensación económica por parte de las autoridades mexicanas, decididas ya a poner punto y final a una etapa de desencuentros formales y encuentros oficiosos. México reanudó relaciones en un momento en que España todavía no había culminado su Transición política. La vigencia de los principios del Movimiento y del entramado legal franquista era plena hasta la aprobación definitiva de la Constitución de 1978, una constitución en la que no pudieron participar los republicanos liberales que no fueron legalizados a tiempo. Sin embargo, las autoridades mexicanas mostraron mucha prisa por consolidar las relaciones como demostró el viaje oficial de López Portillo a España en octubre de 1977 en un contexto de crisis económica y política preocupante en México.

68 Junquera, 1979. Duarte Rivas, 1994.

69 Cordero, 2005: $146 \mathrm{~s}$.

70 "Posibilidades de una solución republicana en Cataluña y el Estado español", en República Española, Acción Republicana Democrática Española, 44 (México, 28 de febrero de 1977): 3 y 4. Se puede consultar en la Fundación Pablo Iglesias, P. 2616.

71 Véase el folleto Voces amigas en el camino hacia la libertad, Centro Republicano Español, México DF, 1977, Ateneo Español de México. 
A MODO DE CONCLUSIONES

A lo largo de estas páginas he tratado de realizar un repaso sumario a la evolución de las complejas relaciones entre México y España durante las décadas centrales del siglo XX. Las autoridades mexicanas, con ayuda de los propios refugiados españoles, fueron articulando un discurso legitimador basado en el profundo contenido ético de la política mexicana con respecto a España. A través de estos discursos, se fue forjando en el imaginario mexicano y también en el imaginario colectivo del exilio republicano la imagen de que México y la dictadura franquista mantenían rotos todos los canales de comunicación como resultado de aquella política. El México posrevolucionario, paladín de la democracia, que abrió sus puertas a los refugiados, representantes de la España de la cultura, la libertad y el pensamiento, se convertía así en un ejemplo de dignidad política para el mundo civilizado, el representante más claro de la oposición al franquismo, el actor antagónico en el complicado escenario internacional de los años treinta. Sin duda, la figura de Lázaro Cárdenas quedó asociada indisolublemente a esta política internacional. El presidente más querido por los mexicanos de todo el siglo XX, ensalzado en los laicos altares de los republicanos españoles, se erigió en el referente por antonomasia de esa política internacional. Su política de acogida, sin duda la más generosa de cuantos países recibieron exiliados republicanos españoles, ha sido presentada como un acto filantrópico y desinteresado, una política de puertas abiertas sin restricciones. Así, se fueron conformando una serie de imágenes que a fuerza de ser repetidas han articulado ese discurso oficial, que olvidaba algunos de los hechos ocurridos tras la salida de Cárdenas del poder y que hemos ido presentando en estas páginas.

Si los inicios del periodo estudiado la solidaridad jugó un papel esencial, la propia evolución de las relaciones entre los gobiernos mexicanos y las instituciones republicanas en el exilio muestran como el PRI, y sus sucesivos mandatarios, instrumentalizaron la situación en beneficio propio, dentro de una campaña de imagen hacia dentro y hacia fuera de las fronteras mexicanas, minimizando el coste de su apoyo, restringido en la mayoría de los casos al terreno de lo simbólico. Sin embargo, sin ese apoyo difícilmente hubiesen podido sobrevivir, a pesar de la tenacidad de unos pocos republicanos, en el mantenimiento de la legitimidad republicana. Abandonadas por casi todos, incluidos muchos de los propios exiliados, las instituciones permanecieron hasta su disolución gracias al reconocimiento de México y Yugoslavia, dos países de segunda fila en el concierto internacional que, sin embargo ocupaban posiciones estratégicas en un mundo polarizado. México hizo de la causa 
republicana un elemento de legitimación de su política exterior y como un modo de afianzar su independencia con respecto a Estados Unidos.

La búsqueda de un papel de mayor relevancia en el panorama internacional por un lado, la recepción de un capital humano bien formado por otro, son elementos que deben ser valorados en su justo término. A partir de los años cuarenta y hasta los años sesenta del siglo pasado, México vivió un despegue económico que contribuyó a transformar y modernizar el país. Sin necesidad alguna de mantener relaciones con la dictadura española, las autoridades mexicanas primaron una imagen proyectada hacia el interior de México de abierta hostilidad con la España franquista, reforzando así su compromiso con la democracia y contentando las aspiraciones de la cada vez más influyente comunidad de refugiados españoles. Así las relaciones bilaterales estuvieron permanentemente mediadas por los republicanos españoles al menos en la parte oficial. Como hemos podido comprobar, el mantenimiento de las relaciones diplomáticas con la España democrática restablecidas en 1945, no impidieron que se sucediesen los contactos con la España dictatorial. Si en los primeros años la dictadura franquista realizó importantes esfuerzos para conseguir el restablecimiento de las relaciones, con su progresiva consolidación internacional y especialmente con la protección de Estados Unidos, la dictadura dejó de concebir este asunto como prioritario. Para el México oficial, su política hacia España constituyó una cierta tradición que aportaba notables réditos en su política interna y contribuía a maquillar su progresiva derechización. El doble discurso de Luis Echeverría representa claramente el paradigma de esas contradicciones. Por un lado, la represión de la disidencia en el interior en una dictadura de partido, por otro la solidaridad hacia todo movimiento político de izquierdas perseguido en España y Latinoamérica.

Con el despegue económico protagonizado por España en los años sesenta y especialmente con el inicio de la Transición política, México volvió a mirar hacia la Península con interés creciente por el restablecimiento de las relaciones bilaterales. Lo hicieron incumpliendo sus compromisos adquiridos de no cambiar la situación diplomática mientras España continuase siendo una dictadura. En el momento en que cancelaron las relaciones con la República española, la legislación de la dictadura continuaba vigente y en unas condiciones que impedían la participación política de sus protegidos y admirados republicanos, que desaparecieron de la escena política española, empobreciendo notablemente la vida política democrática de la España presente. 
BIBLIOGRAFÍA:

Alonso García, María del Rosario, Historia, diplomática y propaganda de las instituciones de la república española en el exilio 1945-1962, Madrid, Fundación Universitaria Española, 2004.

Aub, Elena, Palabras del exilio: historia del ME/59; una última ilusión, México D.F., Consejo Nacional para la Cultura y las Artes, 1992.

Aznar Soler, Manuel, “Movimiento español 1959: literatura y política de la segunda generación exiliada en México", Manuel Aznar Soler y José Ramón López García (coords.), El exilio republicano y la segunda generación, Sevilla, Renacimiento, 2011: 143-198.

Botella Pastor, Virgilio, Entre memorias. Las finanzas del gobierno republicano español en el exilio, Madrid, Renacimiento, 2002.

Cabeza Sánchez Albornoz, Sonsoles, Historia política de la Segunda República en el exilio, Madrid, Fundación Universitaria Española, 1997.

Carrillo, Santiago, Memorias, Barcelona, Planeta, 1993.

Condés Lara, Enrique, Represión y rebelión en México 1959-1985, México, Porrúa, 2007.

Cordero, Inmaculada, Los transterrados y España. Un exilio sin fin, Huelva, Universidad de Huelva, 1997.

Cordero, Inmaculada, El espejo desenterrado, España en México, 1975-1982, Sevilla, Fundación El Monte, 2005.

Duarte Rivas, Rodolfo (ed.), Jesús Reyes Heroles y la reforma política, México, Fondo de Cultura Económica, 1994.

Escudero, María Amparo, "Las relaciones entre los exiliados republicanos y la antigua colonia de residentes en México", Javier Tusell, Alicia Alted y Abdón Mateos (eds.), La oposición al régimen de Franco, tomo 1, vol. 2, Madrid, UNED, 1990: 297-306.

Faber, Sebastian, Exile and Cultural Hegemony, Spanish Intellectuals in México, 19391975, Nashville, Vanderbilt University press, 2002.

Fuentes Mares, José, México en la Hispanidad, ensayo polémico sobre mi pueblo, Madrid, Instituto de Cultura Hispánica, 1949.

Gilly, Adolfo, El cardenismo, una utopía mexicana, México, Cal y Arena, 1994.

González Gómez, Claudia y Díaz Sánchez, Gerardo (coord.), Exilios en México, siglo XX, Morelia, Universidad Michoacana de San Nicolás de Hidalgo, 2008.

Gordón Ordás, Félix, Mi política fuera de España, tomo III, México, edición del autor, 1969. 
Gordón Ordás, Félix, Mi política fuera de España, tomo IV (I), México, edición del autor, 1970.

Guillén, Fedro, Fabela y su tiempo, España Cárdenas, Roosevelt, México, Imprenta Arana, 1976.

Herrerín, Ángel, El dinero del exilio, Indalecio Prieto y las pugnas de posguerra (19391947), Madrid, Siglo XXI, 2007.

Hoyos Puente, Jorge de, "La construcción del imaginario colectivo del exilio republicano en México: los mitos fundacionales", Encarna Nicolás y Carmen González (eds.), Ayeres en discusión. Temas claves de Historia contemporánea hoy, Murcia, Universidad de Murcia, 2008. (CD): 1-20.

Hoyos Puente, Jorge de, "Las Españas del exilio, una mirada a las culturas políticas refugiadas en México, 1939-1950", Estudios Migratorios Latinoamericanos, 69 (Buenos Aires, julio-diciembre 2010): 235-262.

Hoyos Puente, Jorge de, "Rumbo a México en tiempo de incertidumbres. 1939 en las culturas políticas de la izquierda española” Abdón Mateos y Agustín Sánchez Andrés (eds.), Ruptura y transición. España y México, 1939, Madrid, Ed. Eneida, 2011: 117-136.

Junquera, Rafael, La Reforma política, Xalapa, Universidad Veracruzana, 1979.

Lemus, Encarnación, "El gobierno republicano en París y las relaciones España-Francia en la década de los cincuenta", Fernando Martínez, Jordi Canal y Encarnación Lemus (eds.), París ciudad de acogida. El exilio español durante los siglos XIX y XX, Madrid, Marcial Pons, 2010: 307-339.

Lida, Clara E. y Matesanz, José Antonio, El Colegio de México, una hazaña cultural, 1940-1962, México, El Colegio de México, 1990.

Lida, Clara E., "Lázaro Cárdenas y la Guerra Civil Española", Claves de Razón Práctica, 57 (Madrid, 1995): 66-72.

Lida, Clara E. (ed.) México y España en el primer franquismo, 1939-1950, México, El Colegio de México, 2001.

Mateos, Abdón, "Tiempos de guerra, tiempos de desesperanza. La política de Ávila Camacho hacia España y el exilio republicano en México, 1940-1943", Historia Mexicana, LIV/2 (México, octubre-diciembre 2004): 405-443.

Mateos, Abdón, De la guerra civil al exilio. Los republicanos españoles y México. Indalecio Prieto y Lázaro Cárdenas, Madrid, Biblioteca Nueva, 2005.

Matesanz, José Antonio (coord.), México y la República española, antología de documentos, 1931-1977, México, Centro Republicano Español de México, 1977.

Matesanz, José Antonio, Las raíces del exilio. México ante la guerra civil española 19361939, México DF, El Colegio de México, 1999.

Medin, Tzvi, Ideología y praxis política de Lázaro Cárdenas, México, Siglo XXI, 1973. 
Mendoza, Maria Luisa, Allende el bravo, los días mexicanos, México, Editorial Diana, 1973.

Meyer, Lorenzo, "La Guerra Fría en el mundo periférico: el caso del régimen autoritario mexicano. La utilidad del anticomunismo discreto", Daniela Spencer (coord.), Espejos de la Guerra Fría, México, América Latina y el Caribe, México, CIESAS-Porrúa, 2004: 95-117.

Moctezuma Barragán, Javier (ed.), Francisco J. Mújica. Un romántico rebelde, México, Fondo de Cultura Económica, 2001.

Ojeda Gómez, Mario, México, el surgimiento de una política exterior activa, México, Secretaria de Educación Pública, 1986.

Ortuño, Manuel (ed.), Diplomáticos de Cárdenas. Una trinchera mexicana en la guerra civil (1936-1940), Madrid, Trama editorial, 2007.

Pardo, Rosa, Con Franco hacia el Imperio. La política exterior española en América latina, 1939-1945, Madrid, UNED, 1995.

Payá, Emeterio, Los niños españoles de Morelia, el exilio infantil en México, México, EDAMEX, 1985.

Paz Sánchez, Fernando, Narciso Bassols, México, Editorial Nuestro Tiempo, 1986.

Pérez Montfort, Ricardo, Hispanismo y Falange, los sueños imperiales de al derecha española, México, Fondo de Cultura Económica, 1992.

Pérez Montfort, Ricardo, "La mirada oficiosa de la Hispanidad. México en los informes del ministerio de Asuntos Exteriores Franquista, 1940-1950", Clara E. Lida (coord), México y España en el primer franquismo, 1939-1950, México, El Colegio de México, 2001: 61-119.

Pla, Dolores, Los niños de Morelia. Un estudio sobre los primeros refugiados en México, México, INAH, 1985.

Rodríguez de Magis, María E., "Sobre la incomprensión de la postura mexicana frente a Cuba", Foro Internacional, 6/1 (México DF, julio-septiembre 1965): 121-135.

Salazar, Delia (coord.), Xenofilia y Xenofobia en la historia de México, siglos XIX y XX, Homenaje a Moisés González Navarro, México, INM-INAH, 2006.

Sánchez Andrés, Agustín (ed.), Un capítulo de la memoria oral del exilio: los niños de Morelia, Madrid/México, Comunidad de Madrid/Universidad Michoacana de San Nicolás de Hidalgo, 2002.

Sánchez Andrés, Agustín y Pereira Castañares, Juan Carlos (eds.), “España y México, doscientos años de relaciones, 1810-2010", Morelia, Universidad Michoacana de San Nicolás de Hidalgo, Instituto de Investigaciones Históricas, 2010.

Sánchez Cervelló, José, La II República en el exilio, 1939-1977, Barcelona, Planeta, 2011. 
Serrano Migallón, Fernando, Isidro Fabela y la diplomacia mexicana, México, Fondo de Cultura Económica, 1981.

Sola Ayape, Carlos, Entre fascistas y cuervos rojos, México, Editorial Porrúa/Tecnológico de Monterrey, 2008.

Tabanera, Nuria, "La Segunda República y México 1931-1936", Historia 16, 205 (Madrid, 1993): 26-35.

Tirado, Arantxa, "La política exterior del México cardenista hacia la Segunda República española. El caso del exilio republicano en México", Trabajo de doctorado inédito, Universidad Autónoma de Barcelona, 2007.

Tusell, Javier (dir.), La política exterior de España en el siglo XX, Madrid, UNED, 1997.

Yankelevich, Pablo (coord.), México, país de refugio. La experiencia de los exilios en el siglo XX, México DF, Instituto Nacional de Antropología e Historia, 2002.

Yankelevich, Pablo, Ráfagas de un exilio, argentinos en México 1974-1983, México, El Colegio de México, 2009.

Yuste de Paz, Miguel Ángel, La II República española en el exilio en los inicios de la guerra fría (1945-1951), Madrid, Fundación Universitaria Española, 2005.

Fecha de recepción: 5 de abril de 2012.

Fecha de aceptación: 12 de noviembre de 2012.

\section{Mexico and Spanish Republican Institutions in Exile: from the Support of the Cardenas Regime to Political Instrumentalization by the PRI, 1939-1977}

This article reviews the circumstances of the support afforded by successive Mexican governments to the Spanish Second Republic in exile during Franco's dictatorship. Mexican aid did represent one of the main sources of strength for the Republican cause in exile, even though it has been somewhat mythologized. The study focuses on some of the main keys to understanding this attitude and why it was sustained for such a long time by Mexican authorities.

KeY WORDS: PRI; Mexico; spanish republican exile; Spain. 